University of Nebraska - Lincoln

DigitalCommons@University of Nebraska - Lincoln

Forest biomass mapping from lidar and radar synergies

\author{
Guoqing Sun \\ University of Maryland, guoqing.sun@gmail.com \\ K. Jon Ranson \\ NASA's Goddard Space Flight Center \\ Z. Guo \\ Chinese Academy of Sciences \\ Z. Zhang \\ Beijing Normal University \\ P. Montesano \\ Science Systems and Applications, Inc \\ See next page for additional authors
}

Follow this and additional works at: https://digitalcommons.unl.edu/nasapub

Part of the Physical Sciences and Mathematics Commons

Sun, Guoqing; Ranson, K. Jon; Guo, Z.; Zhang, Z.; Montesano, P.; and Kimes, D., "Forest biomass mapping from lidar and radar synergies" (2011). NASA Publications. 92.

https://digitalcommons.unl.edu/nasapub/92

This Article is brought to you for free and open access by the National Aeronautics and Space Administration at DigitalCommons@University of Nebraska - Lincoln. It has been accepted for inclusion in NASA Publications by an authorized administrator of DigitalCommons@University of Nebraska - Lincoln. 


\section{Authors}

Guoqing Sun, K. Jon Ranson, Z. Guo, Z. Zhang, P. Montesano, and D. Kimes 


\title{
Forest biomass mapping from lidar and radar synergies
}

\author{
Guoqing Sun ${ }^{\mathrm{a}, *}$, K. Jon Ranson ${ }^{\mathrm{b}}$, Z. Guo ${ }^{\mathrm{c}}$, Z. Zhang $^{\mathrm{d}}$, P. Montesano ${ }^{\mathrm{e}}$, D. Kimes ${ }^{\mathrm{b}}$ \\ a Dept. of Geography, University of Maryland, College Park, MD, USA \\ b Biospheric Sciences Branch, NASA's Goddard Space Flight Center, Greenbelt, MD, USA \\ c State Key Laboratory of Remote Sensing, Institute of Remote Sensing Applications, Chinese Academy of Sciences, P.0. Box 9718, Beijing 100101, China \\ d School of Geography, Beijing Normal University, No. 19, Xinjiekouwai Street, Beijing 100875, China \\ e Science Systems and Applications, Inc., 10210 Greenbelt Rd, Lanham, MD 20706, USA
}

\section{A R T I C L E I N F O}

\section{Article history:}

Received 23 May 2009

Received in revised form 2 February 2011

Accepted 26 March 2011

Available online 11 May 2011

\section{Keywords:}

Forest biomass

DESDynI mission

Lidar waveform

LVIS

SRTM

PALSAR

InSAR

SRTM

\begin{abstract}
A B S T R A C T
The use of lidar and radar instruments to measure forest structure attributes such as height and biomass at global scales is being considered for a future Earth Observation satellite mission, DESDynI (Deformation, Ecosystem Structure, and Dynamics of Ice). Large footprint lidar makes a direct measurement of the heights of scatterers in the illuminated footprint and can yield accurate information about the vertical profile of the canopy within lidar footprint samples. Synthetic Aperture Radar (SAR) is known to sense the canopy volume, especially at longer wavelengths and provides image data. Methods for biomass mapping by a combination of lidar sampling and radar mapping need to be developed.

In this study, several issues in this respect were investigated using aircraft borne lidar and SAR data in Howland, Maine, USA. The stepwise regression selected the height indices rh50 and rh75 of the Laser Vegetation Imaging Sensor (LVIS) data for predicting field measured biomass with a $\mathrm{R}^{2}$ of 0.71 and RMSE of $31.33 \mathrm{Mg} / \mathrm{ha}$. The above-ground biomass map generated from this regression model was considered to represent the true biomass of the area and was used as a reference map since no better biomass map exists for the area. Random samples were taken from the biomass map and the correlation between the sampled biomass and co-located SAR signature was studied. The best models were used to extend the biomass from lidar samples into all forested areas in the study area, which mimics a procedure that could be used for the future DESDYnI mission. It was found that depending on the data types used (quad-pol or dual-pol) the SAR data can predict the lidar biomass samples with $\mathrm{R}^{2}$ of $0.63-0.71$, RMSE of $32.0-28.2 \mathrm{Mg} / \mathrm{ha}$ up to biomass levels of $200-250 \mathrm{Mg} / \mathrm{ha}$. The mean biomass of the study area calculated from the biomass maps generated by lidar-SAR synergy was within $10 \%$ of the reference biomass map derived from LVIS data. The results from this study are preliminary, but do show the potential of the combined use of lidar samples and radar imagery for forest biomass mapping. Various issues regarding lidar/radar data synergies for biomass mapping are discussed in the paper.
\end{abstract}

(c) 2011 Elsevier Inc. All rights reserved.

\section{Introduction}

Above-ground biomass cannot be directly measured by any sensor from space. Land cover stratification combined with ground sampling is the traditional method to inventory the biomass of a region. Remote sensing data are playing increasingly important roles in forest biomass estimation. For example, biomass data from field measurements (e.g., FIA - Forest Inventory and Analysis plots) (Blackard et al., 2008) and lidar (GLAS - Geoscience Laser Altimeter System) (Baccini et al., 2008; Nelson et al., 2009) and image data from LANDSAT, MODIS have been used together to perform regional biomass mapping.

Large-footprint lidar systems (Blair et al., 1999) have been developed to provide high-resolution, geo-located measurements of

\footnotetext{
* Corresponding author.

E-mail address: guoqing.sun@gmail.com (G. Sun).
}

vegetation vertical structure and ground elevations beneath dense canopies. Over the past decade, several airborne and space-borne large-footprint lidar systems have been used to make measurements of vegetation. The lidar waveform signature from large-footprint lidar instrument, such as the Scanning Lidar Imager of Canopies by Echo Recovery (SLICER) (Harding et al., 1995, 1998) and the Laser Vegetation Imaging Sensor (LVIS) (Blair et al., 1999) has been successfully used to estimate the tree height and forest above-ground biomass (Drake et al., 2002, 2003; Dubayah \& Drake, 2000; Hofton et al., 2002; Lefsky et al., 1999a,b; Sun et al., 2008). The relationship between forest carbon storage and the vertical structure from lidar waveform is relatively unexplored. Further studies on the data properties, (e.g. the effects of multiple scattering and ground slope on lidar signatures) are needed to verify and improve the retrieval algorithms. One major limitation of current spaceborne lidar systems (i.e., ICESat GLAS) is the lack of imaging capabilities and the fact that they provide sparse sampling information on the forest structure. 
Radar, because of its penetration capability and sensitivity to water content in vegetation, is sensitive to the forest spatial structure and standing biomass. Radar data (both polarimetric and interferometric) have been used for forest biomass estimation (Dobson et al., 1992, 1995; Kasischke et al., 1995; Kurvonen et al., 1999; Le Toan et al., 1992; Ranson et al., 1995, 1997a,b; Ranson \& Sun, 1996; Saatchi et al., 2007) and canopy height estimation (Askne et al., 1997; Hagberg et al., 1995; Kellndorfer et al., 2004; Kobayashi et al., 2000; Simard et al., 2006, 2008; Treuhaft et al., 1996, 2004). These applications require ground sampling data for both training and validation purposes.

The signature from these two kinds of sensors bears commonality due to the biophysical and ecological nature of vegetation communities. The vertical distribution of the reflective surfaces revealed by lidar data implies the overall structure supporting the leaf distribution. The relative importance of microwave backscattering from various tree components (e.g. leaves, branches, trunks) depends on the vertical, as well as horizontal distributions of these components. Reflectance from vegetation canopy is controlled by canopy structure as well as the biochemical composition of the canopy foliage. The use of lidar and radar instruments to measure forest structure attributes such as height and biomass is being considered for future Earth Observation satellite missions. The first such mission to be flown within the next decade is called DESDynI, a combined lidar and radar mission designed to address scientific questions in terrestrial ecosystem structure as well as solid earth and ice dynamics (http:// desdyni.jpl.nasa.gov/, Donnellan et al., 2008). In anticipation of this mission, methods for biomass mapping by combining lidar samples and radar imagery need to be investigated.

Data fusion or synergy is required in remote sensing applications, especially for complex tasks such as mapping of forest structural parameters (Patenaude et al., 2005). Synergistic use of various data and approaches has been applied in various studies. For example, Anderson et al. (2008) used waveform lidar with hyperspectral imagery to estimate three common forest measurements - basal area, above-ground biomass and quadratic mean stem diameter in a northern temperate mixed conifer and deciduous forest. Results suggested that the integrated data sets of hyperspectral and waveform lidar provide improved outcomes over use of either data set alone in evaluating common forest metrics. Using Shuttle Radar Topographic Mission (SRTM) and ICESat/GLAS data, Simard et al. (2008) conducted 3D mapping of mangrove forests. Walker et al. (2007) developed the first-ever high-resolution map of canopy heights for the conterminous U. S. using an empirical InSAR-optical fusion approach. In two investigations of radar-lidar synergy, in a North Carolina pine forest (Nelson et al., 2007) and a wildlife habitat analysis (Hyde et al., 2006), authors found that there was little to be gained or only marginal improvement by adding radar data to lidar data. However, the current satellite lidar technology only samples the earth's surface, whereas radar has the mapping capability required for continuous global biomass mapping. For example Kellndorfer et al. (2010) combined ICESat GLAS, SRTM INSAR and Landsat imagery to make large area estimates of above ground woody biomass and Lefsky (2010) used MODIS and ICESat lidar data together to produce a global map of forest heights. The ecosystem structure component in the DESDynI mission is to measure 3D structure of forests by taking advantage of the spatial continuity of SAR and the direct measurements from lidar samples (Donnellan et al., 2008). This presents a special case for lidar and radar data fusion for mapping forest biomass and other structural parameters globally.

In this study, some issues of combined use of lidar and radar were investigated using data acquired near Howland, Maine, USA. The potential information on biomass from a lidar waveform and the required lidar samples for reliable biomass estimation were studied using field data. The best prediction model was used to generate a reference biomass map from the Laser Vegetation Imaging Sensor (LVIS) data. Random samples were then taken from the biomass map and the correlation between biomass and SAR signature was studied. Proper models were used to extend the biomass from lidar samples into all forested areas in the study area. The new biomass map was compared with the reference biomass map derived from LVIS data. The results of the combined use of lidar samples and radar imagery for forest biomass mapping are presented. Biomass mapping was also performed using field data and SAR data to show that the biomass maps from lidar sample and SAR data were better. Various issues in the lidar/radar data fusion for regional biomass mapping are also discussed in this paper.

\section{Study site and data}

\subsection{Site description and field data}

The test site for this project is the mixed hardwood and softwood forest of the Northern Experimental Forest (NEF), Howland, Maine $\left(45^{\circ} 15^{\prime} \mathrm{N}, 68^{\circ} 45^{\prime} \mathrm{W}\right)$. This site, about $10 \mathrm{Km}$ by $10 \mathrm{Km}$ in size, is used for interdisciplinary forest research and experimental forestry practices. The natural stands in this northern hardwood-boreal transitional forest consist of hemlock-spruce-fir, aspen-birch, and hemlockhardwood mixtures. Topographically, the region varies from flat to gently rolling, with a maximum elevation change of less than $135 \mathrm{~m}$ within the study area. Due to the region's glacial history, soil drainage classes within a small area may vary widely, from excessively drained to poorly drained. Consequently, an elaborate patchwork of forest communities has developed, supporting exceptional diversity in forest structure (Ranson \& Sun, 1994). While a significant part of forests was preserved for research purposes, various forest management and harvesting practices have changed the forest structure. Fig. 1 is a false color ASTER image of July 22, 2002 (15 m pixel resolution) showing different types of forests in the study area.

A stem map (the larger rectangle in Fig. 1), identifying location, diameter at breast height ( $\mathrm{dbh}$ ) and species for every tree with a dbh greater than $3 \mathrm{~cm}$ in a $200 \mathrm{~m}$ by $150 \mathrm{~m}$ area, was collected in 1989 and again in 2003. This data set will be referred to as stem map data in this paper. This data set served well for model simulation and data

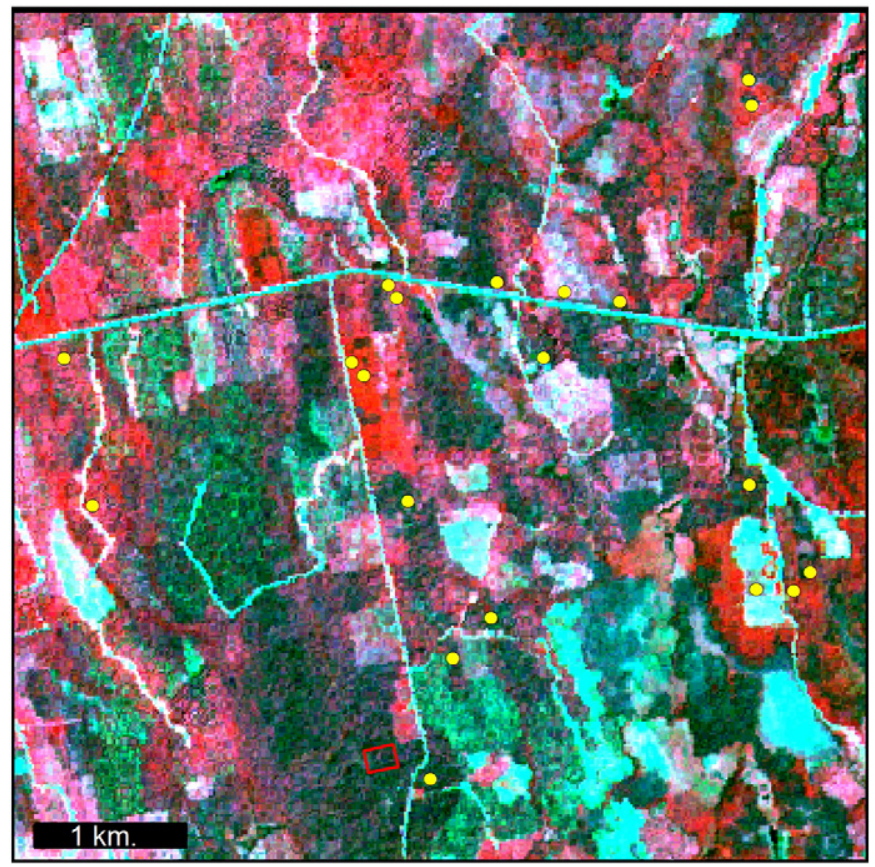

Fig. 1. Study site near Howland, Maine: The larger red rectangle is the location of the stem map. The small red square shows an area with selective cuts. Yellow circles are the field sampled sites in October 2003. 
analyses in previous studies (Kimes et al., 1997; Ranson et al., 1997b). A metal label was attached to every tree in 1989 to aid identification and re-measurement in 2003. The 2003 dataset includes those trees with dbh greater than $3 \mathrm{~cm}$ in 2003 that were not measured in 1989. The canopy biomass can be calculated using dbh from allometric equations listed in Young et al. (1980). The corners of the stem map were located using a Trimble differential GPS instrument with an accuracy of less than $1 \mathrm{~m}$. Fig. 2 shows locations of trees and the LVIS footprints (circles) within the stem map. A total of 112 footprints were completely inside the stem map.

Twenty sites (Fig. 1 and Table 1) across the study area were sampled in October, 2003 for biomass and other forest parameters. In each site three to four plots with radius of 4 or $7 \mathrm{~m}$ were arranged in the center, and $30 \mathrm{~m}$ north, south-west, south-east from the center. The dbh for every tree with a dbh $>3 \mathrm{~cm}$, and the height, crown length and width of 8 trees in each plot were measured. These sites represent a range of forest structures and biomass levels. The locations of the 2003 sampling sites were determined using a backpack borne Garmin V GPS Unit including a Garmin V Personal Navigator and a MBX-3S Differential Beacon Receiver with known accuracy up to $1 \mathrm{~m}, 95 \%$ of the time in good receiving conditions. The major parameters of these sampled forest sites were listed in Table 1.

\subsection{LVIS data}

NASA's Laser Vegetation Imaging Sensor (LVIS) is an airborne laser altimeter system designed, developed and operated by the Laser Remote Sensing Laboratory, Goddard Space Flight Center (GSFC) (Blair et al., 1999). The LVIS system measures the intensity of backscatter returns within $30 \mathrm{~cm}$ intervals and the time delay (or traveled distance by laser beam) through the forest canopy. These recorded signals form a vertical profile or lidar waveform of the lidar footprint, which is a direct measurement of the forest structure. In the summer of 2003, LVIS obtained waveform data for forested sites in New England, generating the most detailed forest structural data sets currently available for these regions. The LVIS data used in this study were acquired on July 26, 2003 and processed at GSFC (Blair et al., 2006; http://lvis.gsfc.nasa.gov). LVIS Ground Elevation (LGE) data were used, which include location (latitude/longitude), surface elevation, and the heights (relative to surface) where $25 \%, 50 \%, 75 \%$

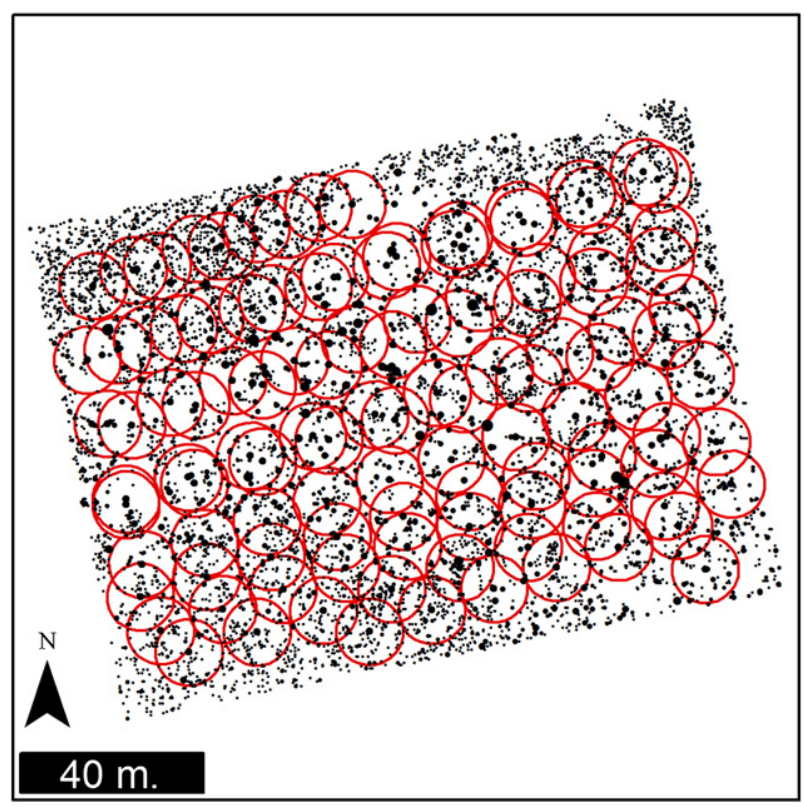

Fig. 2. Stem map - bright dots are locations of trees and the circles represent the LVIS footprints. 112 footprints were completely inside the stem map.
Table 1

Field sample sites in Howland, Maine in 2003: MaxDBH - maximum DBH; Maxht maximum of tree height; DBH_ht - height weighted by Square of DBH; cfb_ratio percentage of biomass from conifer trees; m_biom - mean biomass averaged over sampling sites.

\begin{tabular}{|c|c|c|c|c|c|}
\hline \multirow[t]{2}{*}{ Site } & MaxDBH & Maxht & DBH_ht & cfb_ratio & m_biom \\
\hline & $(\mathrm{cm})$ & $(\mathrm{m})$ & $(\mathrm{m})$ & $(\%)$ & $\left(\mathrm{Kg} / \mathrm{m}^{2}\right)$ \\
\hline 5 & 28.3 & 12.9 & 11.5 & 100 & 7.22 \\
\hline 7 & 15.6 & 17.41 & 12.27 & 0 & 10.37 \\
\hline 8 & 16.5 & 17.91 & 12.65 & 0 & 10.64 \\
\hline 10 & 10.55 & 13.91 & 6.47 & 60 & 6.06 \\
\hline 15 & 25.9 & 21.94 & 14.46 & 73.8 & 16.93 \\
\hline 24 & 32.3 & 23.92 & 20.82 & 6 & 10.03 \\
\hline 25 & 18.1 & 13.66 & 10.5 & 92.2 & 13.85 \\
\hline 27 & 27.7 & 22.55 & 19.79 & 4.4 & 24.88 \\
\hline 30 & 41.8 & 20.44 & 18.37 & 100 & 28.56 \\
\hline 33 & 20.6 & 19.9 & 13.17 & 42.7 & 18.99 \\
\hline 36 & 30 & 21.37 & 17.2 & 41.3 & 21.11 \\
\hline 38 & 17.1 & 13.2 & 11.5 & 100 & 27.10 \\
\hline 39 & 16.1 & 12.71 & 11.48 & 100 & 4.05 \\
\hline $40 \mathrm{~N}$ & 34.2 & 18.81 & 17.16 & 100 & 22.26 \\
\hline 40 & 39.0 & 19.87 & 18.6 & 100 & 19.55 \\
\hline 41 & 33.9 & 22.01 & 19.21 & 41.9 & 21.35 \\
\hline 42 & 27.5 & 17.04 & 14.59 & 30.2 & 15.15 \\
\hline 43 & 32.3 & 18.35 & 15.5 & 98.8 & 11.46 \\
\hline 46 & 38.6 & 19.79 & 15.41 & 100 & 16.96 \\
\hline 48 & 34.9 & 19.45 & 15.75 & 96.3 & 14.00 \\
\hline
\end{tabular}

and $100 \%$ of the waveform energy occur. These quartile heights are referred as rh25, rh50, rh75 and rh100 to represent the relative heights in this study. ENVI's gridding function, which uses Delaunay triangulation of a planar set of points, was used to grid the LVIS LGE data to $15 \mathrm{~m}$ ASTER base images. Fig. 3A is a false color image showing the rh50 (R), rh100 (G), and rh25 (B) from LVIS data.

The quartile heights are direct measurements of the vertical profile of canopy components. Waveform measures are a function of the

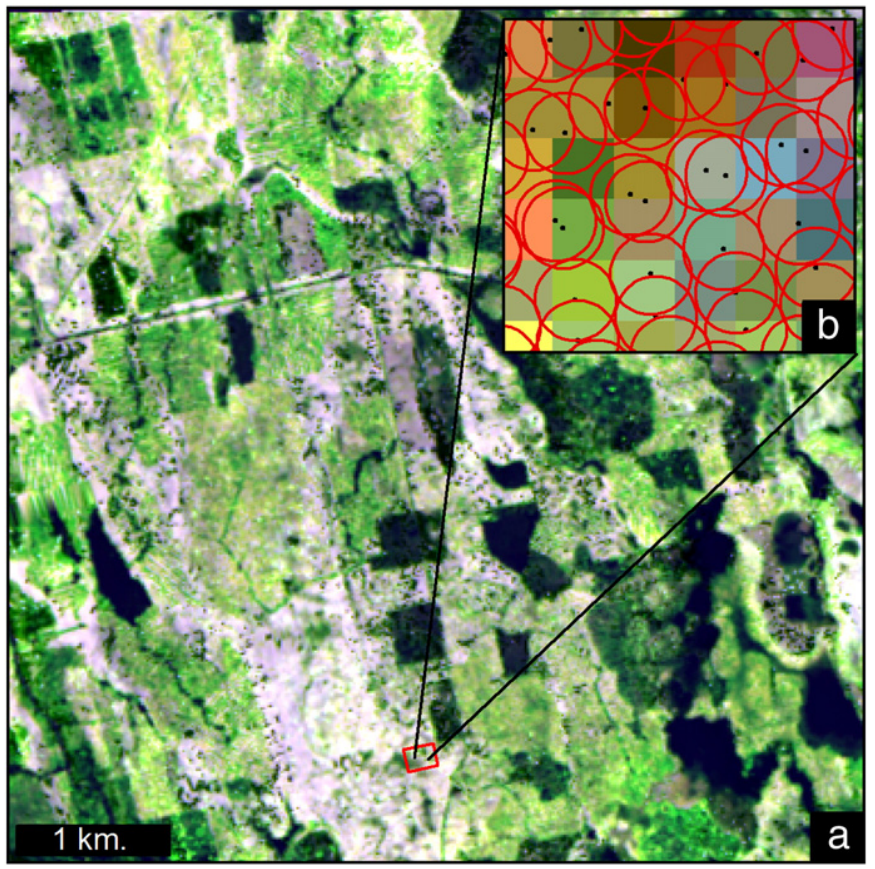

Fig. 3. A) Gridded LVIS rh50 (Red), rh100 (Green), and rh25 (Blue), solid red rectangle is the stem map used in this study. The area delineated by the small red square is an area with selective cutting. The top canopy height remains unchanged, but the density of trees was reduced as shown on ASTER images. B) Centers of LVIS footprints overlaid on the $15 \mathrm{~m}$ ASTER image, showing the sampling density of LVIS data in the region. 
complex and variable 3-D structure of canopy components and their spectral properties, as well as the spectral properties of the ground/ litter. The rh25 and rh50 are lower for the selectively cut areas as seen in Fig. 3A. In the area around the stem map in Fig. 3A (the solid red rectangle) all three relative height indices are high so they appear white in the false color image. This corresponds to a forest area without disturbances. When the trees were partially cut (the red square), the relative lidar signature returned from tree crowns was reduced and that from the ground surface increased resulting in the lower values of rh 25 and rh50, so the false color of the selectively cut area in Fig. 3A does not appear white but green. Fig. 3B depicts the centers of LVIS footprints overlaid on the $15 \mathrm{~m}$ ASTER image, showing that there were more than 20 footprints in a window of $5 \times 515 \mathrm{~m}$ pixels.

\subsection{SAR and LANDSAT images}

PALSAR images from the Japanese Aerospace Exploration Agency (JAXA) Advanced Land Observing System used in this study are listed in Table 2. Data were ordered as Level 1.1 data. The spatial resolution of the single-look image is $3.556 \mathrm{~m}$ and $9.369 \mathrm{~m}$ in azimuth and range directions, respectively. As a Level 1.1 product, the data were radiometrically calibrated and in complex format. The data in Table 2 form two pairs of InSAR data, and were processed using ROI_PAC software (Repeat Orbit Interferometry Package, http://www. roipac.org/) to create coherence data. SRTM data were downloaded from the USGS site (http://srtm.usgs.gov/), and the height of the scattering phase center was derived from the SRTM DEM minus the surface elevation measured with LVIS. Fig. 4 shows false color images of SAR data.

While the forest area surrounding the stem map has been preserved for scientific studies, the rest of the forests in the study area have been actively managed. The logging methods were changed from clear-cut in the 1980s, to strip-cuts in the 1990s and to selectcuts (shelter wood cuts) after 2000. Since the data used in this study were from different years of 2000, 2003 and 2007, the logged areas during this period need to be identified. Three LANDSAT ETM + data acquired on July 2, 2000, September 10, 2003 and July 22, 2007 were used to map the changed areas, so they could be omitted for this study.

\section{Method}

\subsection{Image data processing}

Rasterized LVIS height indices data, SAR data, and the phase center height from SRTM and LVIS DEM data were all co-registered with the $15 \mathrm{~m}$ ASTER base images. LVIS indices and SAR data were extracted from the co-registered images using windows with various sizes $(1 \times 1,3 \times 3,5 \times 5)$ corresponding to various scales $(15 \mathrm{~m}, 45 \mathrm{~m}, 75 \mathrm{~m})$, respectively.

Definiens Developer 7.0 (Definiens, 2009), which allows for the automatic and optimal delineation of local homogenous regions, was used to perform a segmentation of ETM+ images. The polygon segments formed were classified to create a change mask. Fig. 5A

\section{Table 2}

ALOS PALSAR data used in the study: all data were acquired around 3 am with ascending orbits. The numbers in bold were use to identify the data variables in this paper. PLR - polarimetric mode; FBD - Dual-pol (HH and HV) mode.

\begin{tabular}{llll}
\hline Image name & Date & Sensor mode & Angle \\
\hline ALPSRP065210900 & $4 / 16 / 2007$ & PLR & 21.5 \\
ALPSRP071920900 & $6 / 1 / 2007$ & PLR & 21.5 \\
ALPSRP077610890 & $7 / 10 / 2007$ & FBD & 34.3 \\
ALPSRP084320890 & $8 / 25 / 2007$ & FBD & 34.3 \\
\hline
\end{tabular}
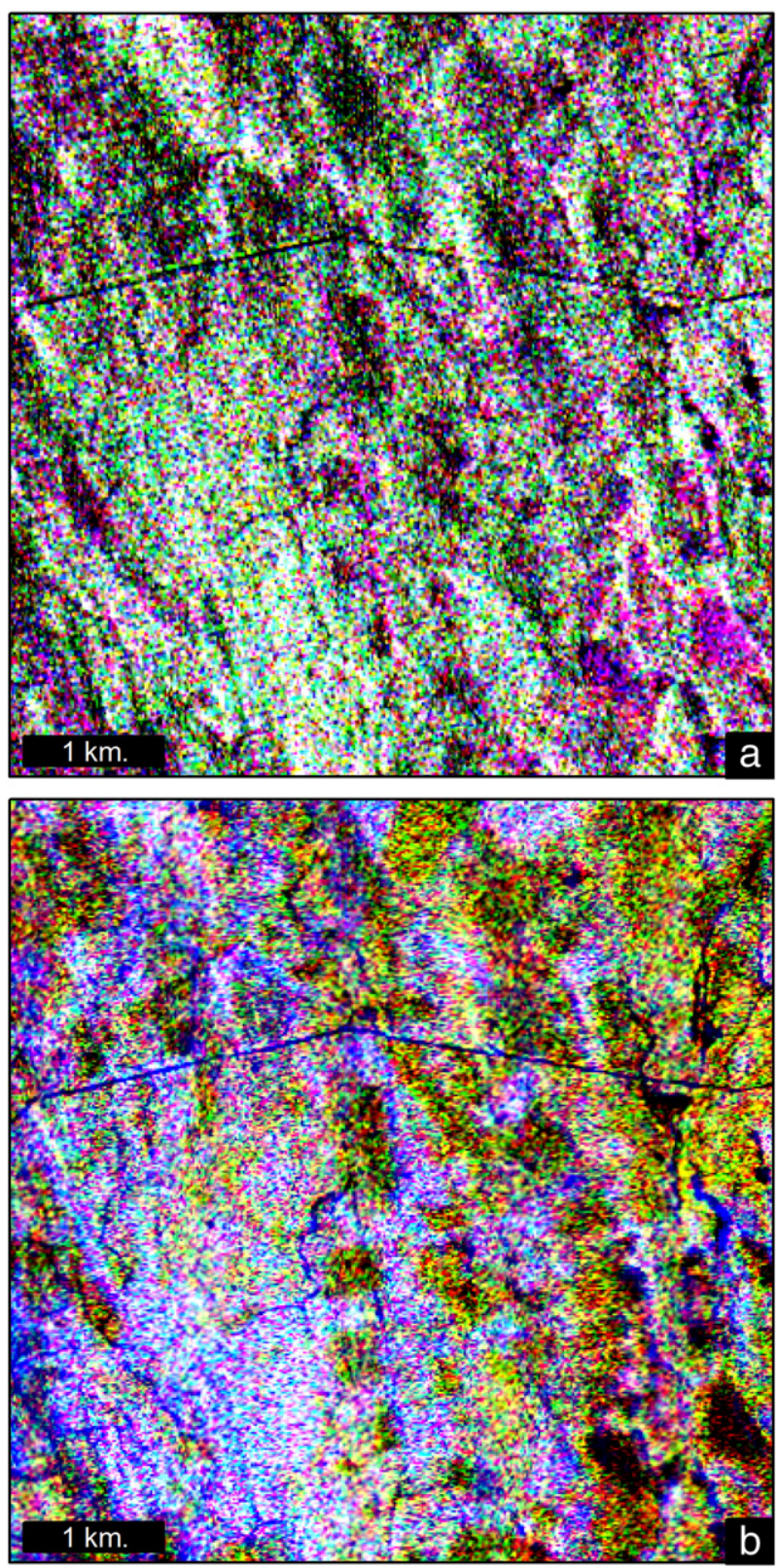

Fig. 4. ALOS PALSAR data: A) polarimetric data acquired on April 16, 2007: Lhh (red), Lhv (green), Lvv (blue) and B) Dual-pol data acquired on July 10, 2007 and SRTM phase center data in 2000: Lhh (red), Lhv (green), phase center height (blue). The phase center height was the difference between SRTM DEM and the ground surface elevation from LVIS data.

shows the polygon segments overlaid on the 2007 ETM+ images, and Fig. 5B shows the changed areas identified from the classification of the polygon segments. A mask (Fig. 5C) was generated to exclude these changed areas and non-forest areas in further analyses. The non-forest areas were identified using $\operatorname{rh} 50 \leq 0$ since the waveform from an ideal bare surface would have rh50 $=0$.

\subsection{Biomass estimation from LVIS data}

\subsubsection{Correlations of forest biomass with lidar waveform indices}

The height indices (relative to the ground surface) rh25, rh50, rh75 and rh100 were extracted from LVIS LGE data for each of the LVIS footprints within stem map (Fig. 2A). Trees within a diameter of the footprint size of $20 \mathrm{~m}$ were used to derive the biomass for each footprint, 

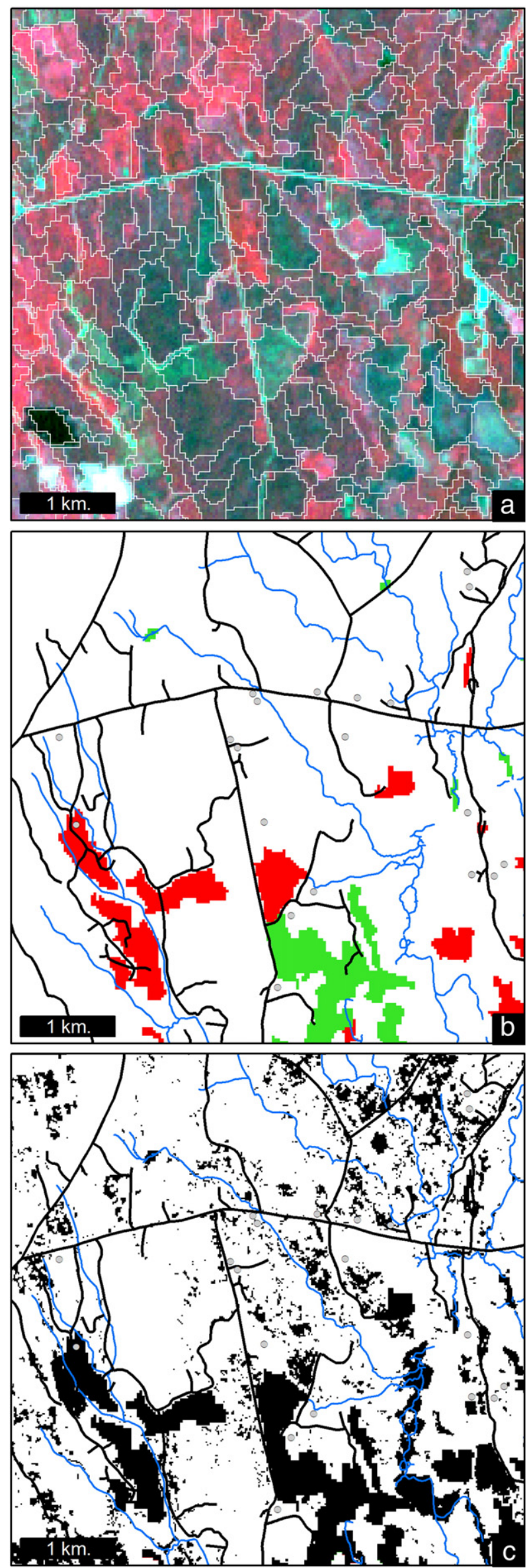

and step-wise regression was performed to select the best prediction model. The correlation was low probably due to the errors in lidar footprint locations and field-measured tree positions.

Aggregation of both biomass measurements and the LVIS indices into a larger unit will reduce measurement uncertainty. The suitable aggregation scale was investigated by randomly sampling the stem map using different pixel sizes. In Fig. 3B, the square pixels are $15 \mathrm{~m}$ pixels from ASTER data. A window with $2 \times 2,3 \times 3$, and $5 \times 5$ pixels will form pixels with sizes of $30 \mathrm{~m}, 45 \mathrm{~m}$ and $75 \mathrm{~m}$. It can be seen that in most cases, there will be several lidar footprints in one of the 30$75 \mathrm{~m}$ pixels. The biomass prediction models at pixel sizes of $15 \mathrm{~m}$, $45 \mathrm{~m}$ and $75 \mathrm{~m}$ were examined. Thirty points were randomly selected within the stem map, such that a pixel with size of $15 \mathrm{~m}, 45 \mathrm{~m}$ and $75 \mathrm{~m}$ was entirely within the stem map. The biomass of these points was calculated from the stem map data using the pixel sizes. The remote sensing data were extracted at these points with a window size of 1, 3 and 5 from co-registered LVIS and SAR data. The stepwise regression function from S-plus (S-Plus, 2010) was used to find the best biomass prediction model. The suitable pixel size for biomass mapping was determined from the analyses.

\subsubsection{Prediction model and biomass mapping from LVIS data}

The 2003 field samples covered forest sites with very different structures. It was found that when the data were extracted from a $3 \times 315 \mathrm{~m}$ window, the correlations between LVIS height indices and biomass were low. The window size was increased to $5 \times 5$ pixels for extracting LVIS and SAR data for the sites sampled in field. The stem map was divided into twelve $50 \mathrm{~m}$ by $50 \mathrm{~m}$ sub-plots and the total above-ground biomass of these sub-plots was calculated. The biomass of these sub-plots was (Mg/ha): 115.3, 119.4, 136.1, 143.8, 149.8, $166.7,170.9,175.5,193.9,206.5,209.6$, and 210.2. These biomass data were used to develop models to generate biomass from LVIS and SAR data. The stepwise regression was used to pick the best LVIS variables for biomass estimation. An above-ground biomass map from LVIS data was generated using the regression model.

\subsection{Forest biomass mapping using field samples and SAR data}

The data from SAR include ALOS PALSAR polarimetric data (PLR mode) from two dates (April 16 and June 1,2007), and dual-pol (HH and HV) images (FSD mode) from two dates (July 10 and August 25, 2007). These PALSAR data were ordered as L1.1, and form two pairs of InSAR data. The data were radiometrically calibrated by JAXA and in complex form $(\mathrm{I}+\mathrm{jQ})$. The equation, Normalized Radar Cross Section (NRCS) $(\mathrm{dB})=10 \log 10\left(<\mathrm{I}^{2}+\mathrm{Q}^{2}>\right)+\mathrm{CF}-32.0$, where $\mathrm{CF}=-83.0$, provided by JAXA (https://auig.eoc.jaxa.jp/auigs/en/doc/an/20090109en_3.html) was used to convert the complex data to NRCS. The complex coherence (Gaveau et al., 2003) between dual-pol data from July 10 and August 25, 2007 was relatively high, so the coherence was used as a variable for biomass estimation. The ratio of $\mathrm{HV}$ to $\mathrm{HH}$ was calculated for each of these PALSAR data. For the polarimetric data, the total power $(\mathrm{HH}+\mathrm{VV}+2 \mathrm{HV})$ was also calculated and used as the independent variables. SRTM elevation data represent the elevation of the scattering phase center over the vegetated areas. By subtracting the surface elevation from LVIS data from the SRTM elevation, the height (from the ground surface to the scattering center within the canopy) can

Fig. 5. (A) Polygons from the multi-resolution segmentation of the Landsat ETM+ scenes (7/2/2000, 9/10/2003, and 7/22/2007) (processed in Definiens Developer 7.0) overlaid on the ETM+ image of 7/22/2007; (B) Map of changed areas produced from segmentation and classification: green areas - areas that changed between 2003 and 2000; red areas - areas that changed between 2003 and 2007. (C) The mask used in this study. Forest areas disturbed during 2000-2007 and the non-forest areas were masked out. 
be obtained. This height was used as a variable in the regression analyses.

The stepwise regression was used to find the best regression models for biomass estimation when the dependent variable is the field biomass and the independent variables include 1) PALSAR PLR data with and without SRTM phase center height, 2) dual-pol PALSAR data with and without SRTM phase center height, and 3) both PLR and dual-pol PALSAR data with and without SRTM phase center height. The best regression models were used to generate biomass maps from SAR data.

\subsection{Extending LVIS biomass samples using SAR data}

\subsubsection{Mapping biomass using LVIS samples and SAR data}

The biomass map from LVIS data was treated as a reference biomass map. The purpose of the study was to investigate the possibility of generating a comparable biomass map using limited samples from LVIS-derived biomass and the SAR imagery. One hundred samples were randomly selected from the areas not masked out by the mask image (Fig. 5C). The LVIS-derived biomass and SAR signatures at each point were extracted using a $5 \times 5$ window. This data set includes the following variables: LVIS derived biomass, srtmlvis_ht, HH, HV, VH, VV intensity, the total power of two polarimetric SAR images, $\mathrm{HH}, \mathrm{HV}$ intensities of two dual-pol SAR images, coherence of $\mathrm{HH}$ polarization of dual-pol images, and the HV to $\mathrm{HH}$ ratio for all SAR images.

The stepwise regression was used to find the best SAR variables for biomass estimation. The regression models were then applied to the same area mapped by LVIS data.

\subsubsection{Model performance and error assessments}

For each biomass estimation equation, the root mean square error (RMSE) was calculated as SQRT(SUM((Bpred - Bref) $\left.)^{2} / \mathrm{n}\right)$. The mean, variance and correlation of the estimated biomass map were calculated and compared.

Re-sampling techniques, such as bootstrapping and jackknifing (Efron, 1981) can provide estimates of the standard error, confidence intervals, and distributions for any statistic without the normality distribution assumption. The lidar sampled biomass was randomly picked in the forested area that was not disturbed during the period of 2000-2007. Bootstrapping was used to investigate the stability or reliability of the prediction models.

\section{Results}

\subsection{Biomass mapping from LVIS data}

\subsubsection{Correlations of forest biomass with lidar waveform indices}

When the waveform indices from 112 LVIS footprints within the stem map were used to predict forest biomass for the $20 \mathrm{~m}$ footprints, the step-wise regression selected all energy quartiles from LVIS LGE data. The relation between the biomass calculated from the forest stem map data and that predicted by the lidar waveform indices was

$\mathrm{B}=17.0-10.3 \mathrm{rh} 25+23.0 \mathrm{rh} 50-22.4 \mathrm{rh} 75+13.7 \mathrm{rh} 100$

with Multiple R-Squared: 0.315, RSE: $21.1 \mathrm{Mg} / \mathrm{ha}$, F-statistic: 12.17 on 4 and 106 degrees of freedom, and a p-value of 3.543e-008.

To investigate the regression relations at different spatial scale, thirty points were randomly selected within the stem map, such that a pixel with size of $15 \mathrm{~m}, 45 \mathrm{~m}$ and $75 \mathrm{~m}$ was entirely within the stem map. The biomass of these points was calculated from the stem map data and the LVIS height indices were extracted at these points with a window size of $1 \times 1,3 \times 3$ and $5 \times 5$ from co-registered imagery data. The results from the stepwise regression show that when the pixel size increased from 15 to 45 and $75 \mathrm{~m}$, the $\mathrm{R}^{2}$ increased from 0.171 to
0.496 and then to 0.725 . Because of the small size of the stem map, when the pixel size increases, there will be much overlap between sampling points. The range of the biomass also decreases. The increases of $\mathrm{R}^{2}$ here may not entirely result from the increase of the pixel size. Nevertheless, the increased averaging reduced the variance of the data caused by the spatial sampling and geo-location mismatching between lidar footprint and tree locations. The $75 \mathrm{~m}$ pixel size was used in the following procedures for biomass mapping.

\subsubsection{Prediction model and biomass mapping from LVIS data}

The best regression equation from stepwise regression using field biomass and LVIS height indices was

$\mathrm{B}=-1.717-6.208 \mathrm{rh} 50+8.625 \mathrm{rh} 75$

with a residual standard error (RSE) of $32.91 \mathrm{Mg} / \mathrm{ha}$, Multiple $\mathrm{R}^{2}$ of 0.70 , F-statistic of 34.08 on 2 and 29 degrees of freedom, and a p-value of $2.43 \mathrm{e}-08$. The relationship between field and predicted biomass shown in Fig. 6 was

$\mathrm{B}_{\text {pred }}=48.5276+0.7015 \mathrm{~B}_{\text {field }}$

with $\mathrm{R}^{2}=0.70$, and the RSE of $27.10 \mathrm{Mg} / \mathrm{ha}$. The RMSE calculated from $\operatorname{SQRT}\left(\operatorname{SUM}\left((\text { Bpred }- \text { Btot })^{2}\right) / 32\right.$ ) was $31.33 \mathrm{Mg} / \mathrm{ha}$. Fig. 7 is the above-ground biomass map from LVIS data using Eq. (2). The model was applied to the entire image, but all the biomass statistics, and the comparisons between different biomass maps were performed on the pixels defined by the mask image (Fig. 5C).

\subsection{Biomass mapping using field biomass data and SAR data}

Stepwise regression was used to find the best variables and models for various combinations of the variables from SAR data. Polarimetric and dual-pol data were treated as two groups of data and stepwise regression was applied separately. Table 3 shows the variables selected by stepwise regression, and the RSE, $\mathrm{R}^{2}$, and p-values of these models. It can be seen from these models that the height of scattering phase center (srtm-lvis_ht) is an important variable, but couldn't predict biomass alone. The coherence of L-band HH data is not a very sensitive variable for biomass estimation. The regression models 3 and 7 in Table 3 were used to generate the biomass map of the study area. The regression relation between predicted from model 3 and the reference biomass is:

$\mathrm{B}_{\text {pred }}=38.2452+0.7019 \mathrm{~B}_{\text {ref }}$

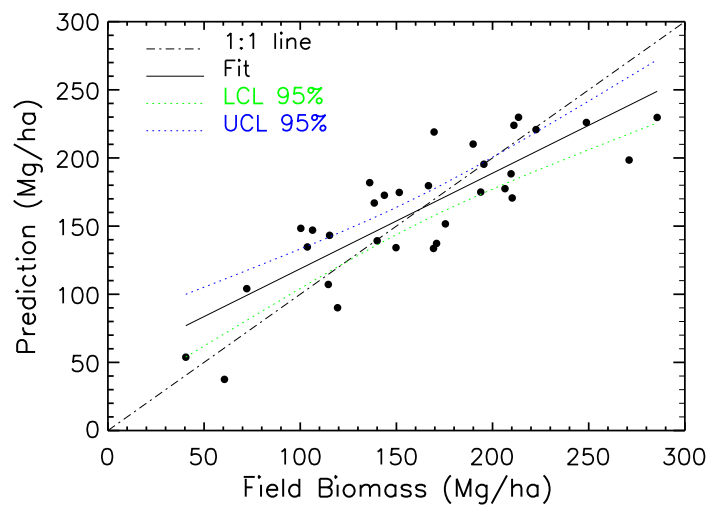

Fig. 6. Predicted biomass vs. field measurements (stars): the biomass prediction model was developed from field sampled forest sites and 12 sub-plots within the stem map 1 . Bpred $=-1.717+6.208 \operatorname{rh} 50+8.625$ rh75, $R^{2}=0.71$, P-value $=2.4 \mathrm{e}-08$. The "fit" line: Bpred $=48.53+0.71$ Bfield, $r^{2}=0.71$, RSE $=27.1 \mathrm{Mg} / \mathrm{ha}$. RMSE calculated from $\operatorname{SQRT}\left(\operatorname{SUM}\left((\text { Bpred - Bfield })^{2}\right) / 32\right)$ is $31.33 \mathrm{Mg} / \mathrm{ha}$. The lines "LCL" and "UCL" are the lower and upper 95\% confidence lines. 


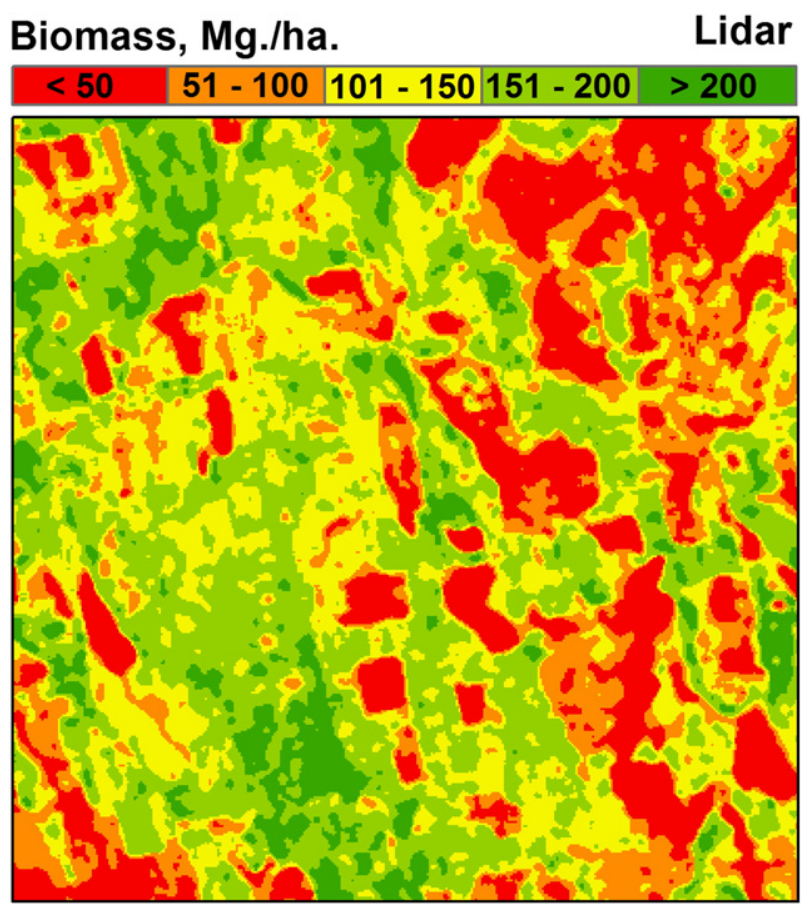

Fig. 7. Biomass map using LVIS height indices from the regression model developed using field biomass data. The image was smoothed using a 5 by 5 window but the pixel size remains as $15 \mathrm{~m}$. The mask shown in Fig. 5C was used in extraction of image data for developing regression model, and for comparisons of the biomass mapping results. Nevertheless, the prediction models were applied to entire images that are shown in this and following images.

with $\mathrm{R}^{2}=0.7019$, and the RSE of $24.32 \mathrm{Mg} / \mathrm{ha}$. The RMSE is $28.73 \mathrm{Mg} / \mathrm{ha}$. The biomass map from model 3 is shown in Fig. 8. Comparing with Fig. 7, the biomass is obviously high, and spatial distribution pattern is vague.

\subsection{Extending LVIS biomass samples using SAR data}

The biomass map shown in Fig. 7 was treated as a reference map. One hundred points were randomly picked from the map shown in Fig. 7. The stepwise regression was used to find the best regression models. Table 4 is a list of these models from stepwise regression when different independent variables were used. The stepwise regression selected different variables from those shown in Table 3. Though the $\mathrm{R}^{2}$ in Table 4 are lower than those in Table 3, the RSE and p-value are also lower, because of larger number of data points. Fig. 9 shows the comparison of predicted biomass using SAR data with the
Biomass, Mg./ha. Radar \begin{tabular}{l|l|l|l|l|l|}
$<0$ & $51-100$ & $101-150$ & $151-200$ & $>200$
\end{tabular}

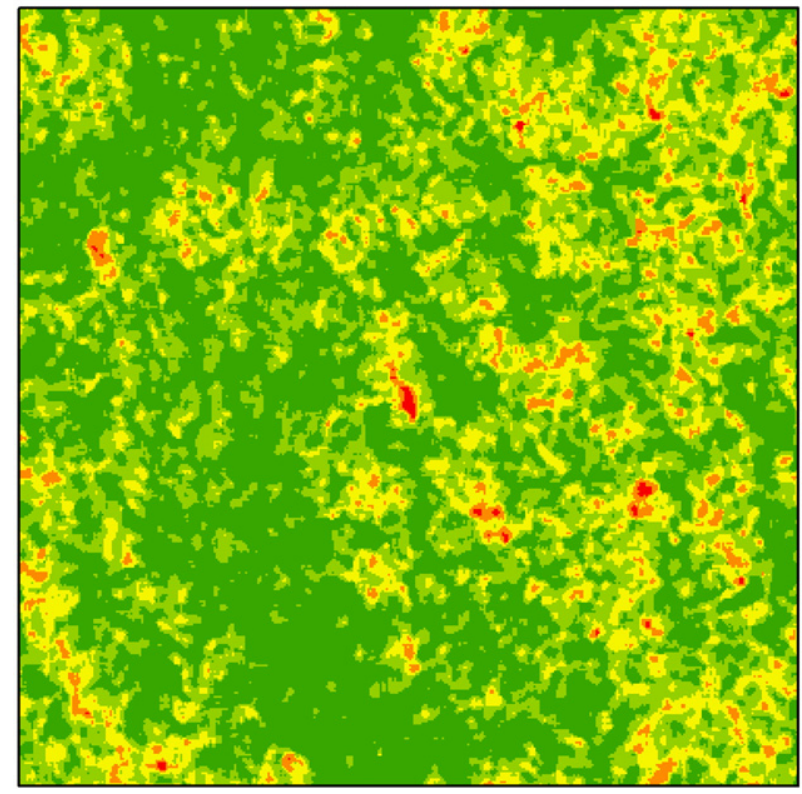

Fig. 8. Biomass map from SRTM phase center height and PALSAR data using regression model developed from field biomass data. The image was smoothed using a 5 by 5 window (pixel size of $15 \mathrm{~m}$ ). Comparing with the biomass in Fig. 7, the biomass level is much higher, and the spatial pattern of biomass distribution is not very clear.

reference biomass using the model 7 in Table 4. The regression relation between predicted and reference biomass is:

$\mathrm{B}_{\text {pred }}=38.8803+0.7126 \mathrm{~B}_{\text {ref }}$

with $\mathrm{R}^{2}=0.71$, and the RSE of $24.06 \mathrm{Mg} / \mathrm{ha}$. The RMSE is $28.21 \mathrm{Mg} / \mathrm{ha}$. Fig. 10 is the biomass map predicted using this model.

\subsection{Model performance and error assessments}

Eqs. (3)-(5) showed that the regression models for biomass estimation from LVIS-field, SAR-field and SAR-LVIS have similar RMSE and $\mathrm{R}^{2}$. But by applying these models on LVIS or SAR data, the resulting biomass maps are quite different. Table 5 shows the statistics of these biomass maps and the correlations of these maps with the reference maps from LVIS-field data. Fig. 11 shows the histograms of above-ground biomass in the areas not masked out by Fig. 5C. First we can see that the two biomass maps from SAR-field are

Table 3

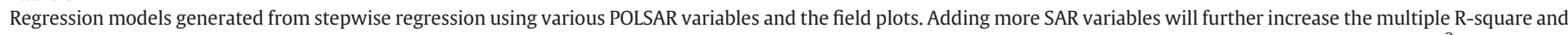

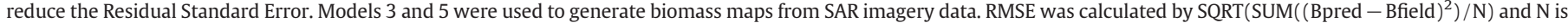
the number of field sites.

\begin{tabular}{|c|c|c|c|c|c|c|}
\hline Model & Variables & Selected var. & $\mathrm{RSE}(\mathrm{Mg} / \mathrm{ha})$ & Mult. $\mathrm{R}^{2}$ & p-value & RMSE \\
\hline 1 & $\mathrm{HH}, \mathrm{HV}, \mathrm{VH}, \mathrm{VV}$ from $4 / 16 / 07$ and 6/1/07 & $\mathrm{HV}, \mathrm{VH}$ of $4 / 16 / 07 ; \mathrm{VH}$ of $6 / 1 / 07$ & 52.01 & 0.28 & 0.025 & \\
\hline 2 & Add total power, $\mathrm{HV} / \mathrm{HH}$ ratio to 1 & $\mathrm{VH}$ of $4 / 16 / 07, \mathrm{VV}, \mathrm{HH}$, totP and $\mathrm{HV} / \mathrm{HH}$ of $6 / 1 / 07$ & 48.7 & 0.41 & 0.012 & \\
\hline 3 & Add srtm-lvis_ht to the variables in 2 & $\begin{array}{l}\text { VH, HV/HH of } 4 / 16 / 07 \mathrm{VV}, \mathrm{HH} \text {, totP and } \mathrm{HV} / \mathrm{HH} \text { of } 6 / 1 / 07 \text {; } \\
\text { srtm-lvis_ht }\end{array}$ & 35.75 & 0.71 & 0.00003606 & 30.96 \\
\hline 4 & $\begin{array}{l}\text { Dual-pol } \mathrm{HH} \text { and } \mathrm{HV}, \mathrm{HV} / \mathrm{HH}, \mathrm{HH} \text { coherence } \\
\text { from two dates in } 2007\end{array}$ & $\mathrm{HH}, \mathrm{HV}, \mathrm{HV} / \mathrm{HH}$ of $8 / 25 / 07$ Coherence of the two $\mathrm{HH}$ images & 54.6 & 0.24 & 0.112 & \\
\hline 5 & Add srtm-lvis_ht to variables in 4 & Srtm-lvis_ht & 51.99 & 0.23 & 0.005528 & \\
\hline 6 & All SAR data (combine variables in 2 and 4) & $\mathrm{HH}$ of $8 / 25 / 07, \mathrm{HV} / \mathrm{HH}$ of $4 / 16 / 07$ and $\mathrm{VV}, \mathrm{HH}$, totP of $6 / 1 / 07$ & 46.52 & 0.51 & 0.004335 & \\
\hline 7 & Add srtm-lvis_ht to 6 & $\begin{array}{l}\mathrm{HH} \text { of } 8 / 25 / 07, \mathrm{VH}, \mathrm{HV} / \mathrm{HH} \text { of } 4 / 16 / 07, \mathrm{VV}, \mathrm{HH} \text {, totP, HV/HH of 6/1/07 } \\
\text { and srtm-lvis_ht }\end{array}$ & 33.92 & 0.75 & 0.0002362 & 28.76 \\
\hline
\end{tabular}


Table 4

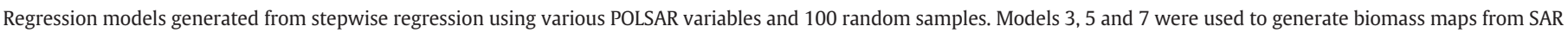
imagery data. RMSE was calculated by SQRT(SUM((Bpred - Bfield $\left.\left.)^{2}\right) / 100\right)$.

\begin{tabular}{|c|c|c|c|c|c|c|}
\hline Model & Variables & Selected var. & RSE (Mg/ha) & Mult. $\mathrm{R}^{2}$ & p-value & RMSE \\
\hline 1 & $\mathrm{HH}, \mathrm{HV}, \mathrm{VH}, \mathrm{VV}$ from $4 / 16 / 07$ and 6/1/07 & $\mathrm{HV}, \mathrm{VV}$ of $4 / 16 / 07 ; \mathrm{VV}, \mathrm{HV}, \mathrm{HH}$ of $6 / 1 / 07$ & 43.6 & 0.36 & $6.294 \mathrm{e}-8$ & \\
\hline 2 & Add total power, $\mathrm{HV} / \mathrm{HH}$ ratio to 1 & $\mathrm{HV}, \mathrm{HV} / \mathrm{HH}$, totP of $4 / 16 / 07, \mathrm{VV}$, totP of $6 / 1 / 07$ & 40.96 & 0.43 & $2.35 \mathrm{e}-10$ & \\
\hline 3 & Add srtm-lvis_ht to the variables in 2 & totP, HV/HH of $4 / 16 / 07 \mathrm{VV}$, totP of 6/1/07; srtm-lvis_ht & 29.64 & 0.70 & 0.0 & 28.73 \\
\hline 4 & $\begin{array}{l}\text { Dual-pol } \mathrm{HH} \text { and } \mathrm{HV}, \mathrm{HV} / \mathrm{HH}, \mathrm{HH} \text { coherence } \\
\text { from two dates in } 2007\end{array}$ & HVof $7 / 10 / 07, \mathrm{HH}, \mathrm{HVHH}$ of $8 / 25 / 07$ Coherence of the two HH images & 44.26 & 0.32 & $2.223 e-07$ & \\
\hline 5 & Add srtm-lvis_ht to variables in 4 & Srtm-lvis_ht $\mathrm{HV} / \mathrm{HH}, \mathrm{HH}$ of $8 / 25 / 07$ & 32.66 & 0.63 & 0.0 & 32.00 \\
\hline 6 & All SAR data (combine variables 2 and 4) & $\begin{array}{l}\mathrm{HH}, \mathrm{HV} / \mathrm{HH} \text { of } 8 / 25 / 07, \mathrm{HV}, \mathrm{VV} \text {, totP, } \mathrm{HV} / \mathrm{HH} \text { of } 4 / 16 / 07 \text { and } \mathrm{VV} \text {, totP of } \\
6 / 1 / 07\end{array}$ & 39.19 & 0.50 & $1.56 \mathrm{e}-10$ & \\
\hline 7 & Add srtm-lvis_ht to 6 & $\begin{array}{l}\mathrm{HH}, \mathrm{HV} / \mathrm{HH} \text { of } 8 / 25 / 07 \text {, totP, } \mathrm{HV} / \mathrm{HH} \text { of } 4 / 16 / 07 \text { and } \mathrm{VV} \text { of } 6 / 1 / 07 \text { and } \\
\text { srtm-lvis_ht }\end{array}$ & 29.26 & 0.71 & 0.0 & 28.21 \\
\hline
\end{tabular}

very similar, as well as the three biomass maps from LVIS-SAR models. The average biomass from SAR-field models was too high. Stem map is a preserved mature stand with an average above-ground biomass of about $170 \mathrm{Mg} / \mathrm{ha}$. The average biomass of the stem map extracted from the biomass maps using the models listed in Table 5 were 161.6, 200.5, 206.7, 141.3, 159.8 and $173.7 \mathrm{Mg} / \mathrm{ha}$, respectively. Large parts of the forest areas in the study area have been harvested since 1980 . The biomass level from Field-LVIS and all LVIS-SAR models is closer to reality (Table 5). The LVIS-SAR models gave similar mean biomass as the Field-LVIS model. The high correlation of these maps with the Field-LVIS map indicates similar spatial distribution patterns as well. The combined RMSE of the two-step models shown in Eqs. (3) and (5) will be $\operatorname{sqrt}\left(31.33^{2}+28.21^{2}\right)=42.16 \mathrm{Mg} / \mathrm{ha}$.

The statistics from bootstrapping of the coefficients of the regression model LVIS-SAR-ALL (Table 5) are shown in Table 6. The means are very close to the observed values and the distributions of these coefficients were close to normal (graphs not shown here).

\section{Discussion}

\subsection{Forest parameters retrieval at lidar footprint scale}

The biomass within a lidar footprint was calculated from trees with trunks inside the footprint. The lidar waveform is the result of reflectance from the tree crowns and the ground surface within the lidar beam while the major biomass is from tree trunks. While a trunk may be inside a footprint, a portion of its crown may fall outside. Similarly, the crown of a nearby tree outside the footprint may be partially illuminated by the lidar beam. This mis-matching will reduce

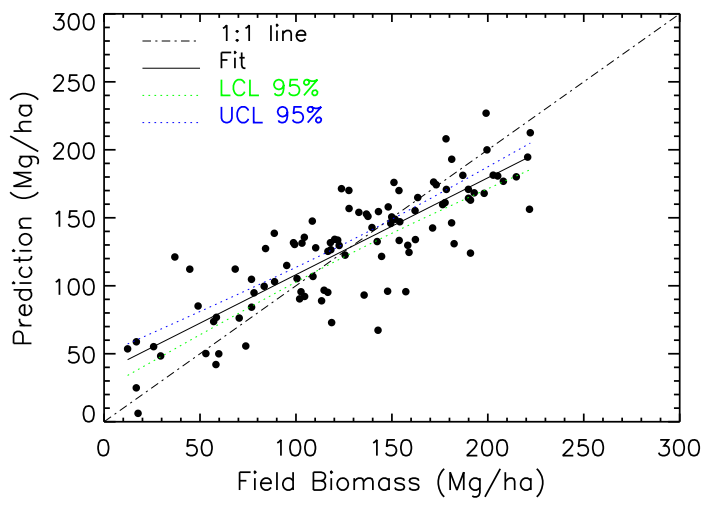

Fig. 9. Biomass predicted by SAR vs. the reference biomass mapped by LVIS data: one hundred random samples were selected in forested area. The line is 1:1 line. Prediction model: $\mathrm{B}=-87.599+12.878$ srtm.lvis +4.799 X10900totp +12.343 X10900hv2hh + 10.172 X20890hv2hh $-8.509 \mathrm{X} 20900 \mathrm{VV}+9.226 \mathrm{X} 20890 \mathrm{HH}$. The prediction results (line "Fit"): Bsar $=36.8803+0.7126$ Blvis, $R^{2}=0.71, R S E=24.06 \mathrm{Mg} / \mathrm{ha}$, p-value is 0 , $\mathrm{RMSE}=28.21 \mathrm{Mg} / \mathrm{ha}$. "LCL" and "UCL" are the lower and upper 95\% confidence lines. the correlation between the biomass calculated for lidar footprints and the lidar waveform indices. The effect depends on the forest spatial structure and the spatial scales at which the forest parameters are to be estimated. At flat areas, the bigger footprint size will have less edge effect. The direct measurements of lidar waveform are the vertical profile of reflectors within the footprint. It is directly related to the tree or canopy height information, but is not direct measurements of the biomass. The correlation between biomass and lidar waveform indices may depend on the species and spatial structure of forests. To define and determine the biomass in a footprint requires clear understanding of the relations among lidar waveform, crown structure and the biomass of forest stands.

\subsection{Aggregation of data into various spatial scales}

No matter what models (multivariable regressions, regression trees, neural networks, etc.) are used to retrieve forest physical parameters from lidar waveform indices, several factors will always cause errors, as long as the model is statistical in nature. In addition to the fact mentioned above, the spatial heterogeneity of the canopy determined in part by its successional stage, natural and anthropogenic disturbances,

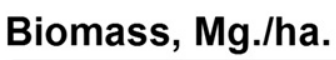
Lidar/Radar

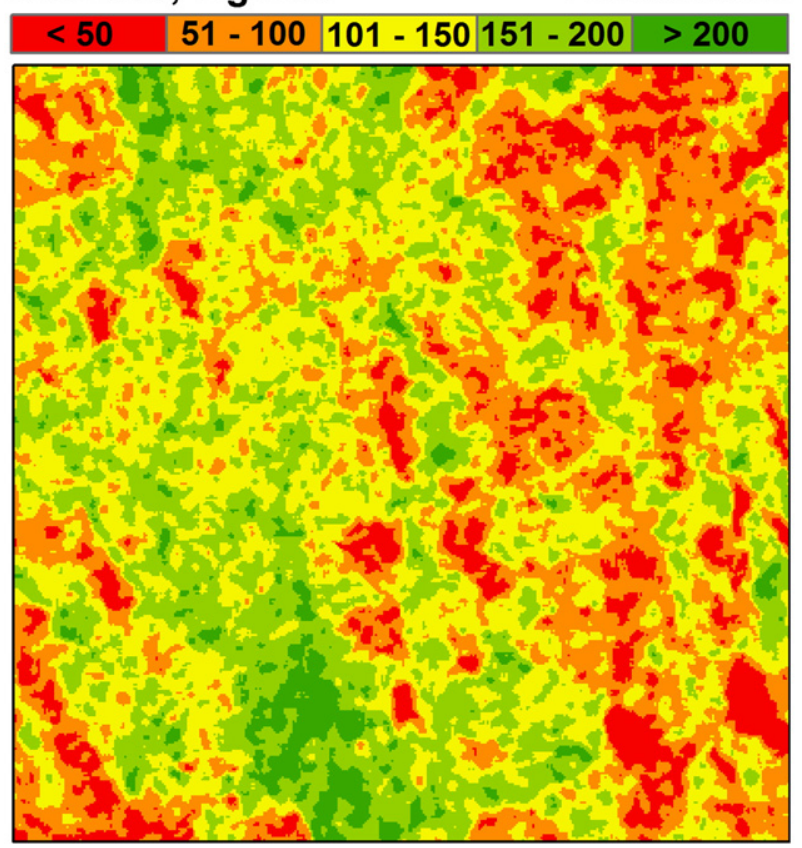

Fig. 10. Biomass map from SRTM phase center height and PALSAR data developed from regression model using random biomass samples from LVIS-derived reference map. The image was smoothed using a 5 by 5 window (pixel size of $15 \mathrm{~m}$ ). 
Table 5

Statistics of biomass maps from different data and methods: 1) Field-LVIS - from LVIS height indices and field data; 2) Field-SAR-PLR - from two PALSAR PLR data and field data; 3) FIELD-SAR-ALL - from the PALSAR PLR data, two dual-pol PALSAR data and field data; 4) LVIS-SAR-PLR and 5) LVIS-SAR-ALL - similar to 2 and 3, 100 randomly selected samples from Field-LVIS were used instead of the field data. 6) LVIS-DualSAR from 100 samples and dual-pol PALSAR data only. The height of the scattering center derived from SRTM and LVIS DEMs was always used in the regression models. The 'Corr' is the spatial correlation among these biomass images.

\begin{tabular}{llrlll}
\hline Models & Min & \multicolumn{1}{c}{ Max } & Mean & Stdev & Corr \\
\hline Field-LVIS & 5.6 & 285.78 & $\mathbf{1 2 6 . 8 2}$ & 57.31 & 1.00 \\
Field-SAR-PLR & 1.15 & 979.58 & 200.61 & 52.63 & 0.59 \\
Field-SAR-ALL & 2.86 & 1095.39 & 200.53 & 55.20 & 0.54 \\
LVIS-SAR-PLR & 1.11 & 318.67 & $\mathbf{1 2 0 . 9 7}$ & 46.93 & 0.78 \\
LVIS-SAR-ALL & 1.12 & 321.75 & $\mathbf{1 2 1 . 1 3}$ & 47.31 & 0.78 \\
LVIS-DualSAR & 0.86 & 272.18 & $\mathbf{1 1 7 . 8}$ & 44.87 & 0.80 \\
\hline
\end{tabular}

and local terrain will cause more error from uncertainties. These include 1) the uncertainties in field data; 2) the uncertainties in waveform indices, and 3) the mis-matching between locations of field sampling and lidar footprints. The tree locations in the stem map were measured by compass and tape in late 1980 without GPS. The locations of field plots sampled in 2003 were determined by hand-hold GPS. The location errors in the data might be a major factor for low correlation between lidar waveform indices and biomass at LVIS footprint scale. Aggregating the data and increasing the samples reduce the uncertainties and improve accuracy. A window of 5 by $515 \mathrm{~m}$ pixels ( $75 \mathrm{~m}$ spacing) was used in this study. Because of the discrepancy in data acquisition dates, and inadequate field sampling data, this issue has not been fully explored in this study.

\subsection{Forest biomass information in SAR data}

This study shows that no single channel of SAR data provides enough information for biomass retrieval, so multiple channels from multiple polarizations, bands and operation modes, and temporal acquisitions were needed. The height of the scattering phase center at C-band from SRTM DEM-LVIS surface elevation was an important variable in this study. Polarimetric SAR interferometry (Pol-InSAR) data has been used to estimate forest height (Cloude \& Papathanassiou, 2003) and then were subsequently converted to forest biomass through forest heightbiomass relation (Caicoya et al., 2010; Mette et al., 2004). The DESDynI mission will provide temporal L-band InSAR data. The height of scattering phase center at $\mathrm{L}$ band derived from these data if surface DEM is available, and the temporal coherence data may play the similar rule in the biomass estimation. The preference of polarizations of SAR data is not very clear in this study probably because of the flat terrain of the study area. When terrain slope exists, the effects of terrain on co-

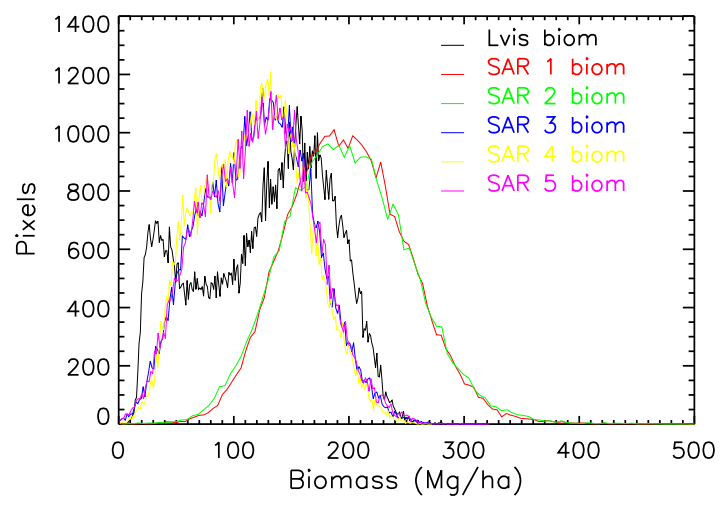

Fig. 11. Histograms of the biomass maps. The mask image of Fig. $5 \mathrm{C}$ excluded about $16.5 \%$ pixels from these images. These six histograms correspond to the six images listed in Table 5. The SAR 1 and 2 biomass maps have significant higher mean biomass than the reference biomass map from LVIS data. polarization signature will be more significant, so cross-polarization should not be excluded from future missions.

\subsection{Comparability of lidar and SAR data for forest biomass estimation}

The regression models developed using randomly selected LVISderived biomass samples and SAR data can generate biomass maps comparable to the biomass map from LVIS data at $75 \mathrm{~m}$ pixel spacing. The multi-channel SAR data can explain more than $70 \%\left(R^{2}\right.$ in Table 4$)$ of the variation of the biomass information contained in the LVIS data. It was found that if the SAR data were used to predict rh50 and rh75, the best regression models selected by stepwise regression had $R^{2}$ of 0.7699 and 0.767 (Equations and plots not shown in the paper). The results from this study show that the SAR data can be used to extend the forest biomass samples at lidar footprints to the entire area covered by SAR data. The mean biomass from Field-LVIS model and LVIS-SAR models are very close. The differences were $4.6 \%, 4.5 \%$ and $7.1 \%$ for the three models shown in Table 5. The spatial correlations between the LVIS-SAR biomass maps and the Field-LVIS map were high: 0.78, 0.78 and 0.8 .

\subsection{Differences of the biomass maps derived from lidar and SAR data using field data}

The biomass map generated from Field-LVIS model is closer to the mean biomass in the study area than the biomass map generated from Field-SAR model. Theoretically, if both LVIS and SAR data can be used to predict biomass, they should give similar results. The only reason for this departure is the inadequate samples of the field biomass for developing the SAR model: it doesn't cover the proper range of forest structures. In this study the number of samples of field data is only $1 / 3$ of the random samples, the Field-SAR model cannot produce the similar biomass maps generated from the LVIS biomass samples and the SAR model.

It is also important to note that the PALSAR data were acquired in 2007 and SRTM data was acquired in 2000 while both the field data and the LVIS data were collected in 2003. Even though the areas with significant changes were excluded in the analyses, the natural changes, such as tree growth and mortality were not considered in the study. In our future studies, data collected at the same time and at various scales will be used to further investigate the issue. This will provide the basis for future analysis.

\subsection{Errors in the biomass maps from one step (lidar only) and two steps (lidar sample and SAR data)}

The RMSE of the Field-LVIS prediction model was $31.33 \mathrm{Mg} / \mathrm{ha}$. This can be improved with more field samples, using more indices from lidar waveform, and more waveform samples by more aggregation. One of the major tasks in algorithm development for the future DESDynI mission is improving biomass estimation from the lidar waveform data. The RMSE of the best LVIS-SAR prediction model (7 in Table 4) was 28.21 Mg/ha. The combined RMSE of the two-step models will be $42.16 \mathrm{Mg} / \mathrm{ha}$. It can be seen from Fig. 9 that the error is relatively even across the entire range $(0-250 \mathrm{Mg} / \mathrm{ha})$ of the biomass, which indicates

Table 6

Statistics from Bootstrap of the regression coefficients of model LVIS-SAR-PLR in Table 5. One thousand re-samples were used in the process. The mean is very close to observed for all coefficients of the model.

\begin{tabular}{lrrrl}
\hline Coefficients of & Observed & \multicolumn{1}{l}{ Bias } & \multicolumn{1}{l}{ Mean } & \multicolumn{1}{l}{ SE } \\
\hline (Intercept) & -8.7599 & 0.4305406 & -8.3294 & 7.3988 \\
srtm.lvis & 1.2878 & -0.0031205 & 1.2847 & 0.1375 \\
X20890HH & 0.9226 & -0.0126622 & 0.9099 & 0.3886 \\
X20890hv2hh & 1.0172 & 0.0006902 & 1.0179 & 0.3510 \\
X10900totp & 0.4799 & 0.0186490 & 0.4985 & 0.2836 \\
X10900hv2hh & 1.2343 & 0.0292449 & 1.2635 & 0.2700 \\
X20900VV & -0.8509 & 0.0180304 & -0.8329 & 0.3407 \\
\hline
\end{tabular}


that the "saturation" may not be a huge problem when multiple SAR variables were used. The accuracy of biomass prediction from lidar waveforms should be lower when the biomass is low or trees are shorter, because in these cases the return from vegetation canopy will merge with those from the ground surface. The signature from canopy was hidden in the ground peak, and the index which is most sensitive to biomass (e.g. rh50) is near zero (very close to the ground peak) and is easily affected by the shape of the ground peak. This may need to be addressed when the two-step method is used in the future.

\subsection{Comparison of histograms of the biomass maps}

Fig. 11 shows that the histogram of Field-LVIS biomass map has two modes. The biomass maps from the LVIS-SAR models have similar means to the Field-LVIS map, but show only little evidence of a bimodal distribution in their histograms. The lower mode of the histogram is around $18-35 \mathrm{Mg} / \mathrm{ha}$, and was from clear cut areas and some other low biomass areas. When the canopy height and biomass are low, the signature from canopy and ground surface will overlap in the lidar waveform, which may cause the uncertainty in biomass estimation from lidar waveform data. This issue may need to be carefully investigated in future studies. The SAR-derived biomass map gave surprisingly high values. This needs to be further investigated, probably by additional field observations.

\section{Concluding remarks}

The purpose of this study was to prove the concept of combined use of lidar-samples and radar-imagery for biomass mapping. The model relating lidar indices to measured biomass explained $71 \%$ of the variation at the aggregated $75 \mathrm{~m}$ pixel resolution. We used the map of biomass values generated from this model as the reference for this study. The results showed that by selecting 100 samples randomly from the reference map and using these samples to develop a prediction model from SAR data, the model can produce a new biomass map which has similar biomass levels and spatial biomass distributions. There is no obvious biomass "saturation" up to $250 \mathrm{Mg} / \mathrm{ha}$, the limit of our measured field data.

Previously, various studies in SAR biomass estimation have been conducted using field measurements of biomass. The consensus is that both polarimetric and interferometric SAR data can be used to estimate forest biomass up to a certain level, depending on radar wavelength. Multiple channels of SAR data from multi-polarization, temporal, interferometric SAR data and transformations of these data can provide adequate information to extend the biomass information at lidar footprints across entire radar images. How to fully use the information and avoid over fitting will be a future research topic. The height of the scattering phase center in the $C$ band derived from SRTM data was an important variable in biomass estimation.

This work represents a preliminary analysis of possible methods that can be used to combine lidar derived biomass (sampled) with SAR image data to provide detailed maps of accurate biomass. The future DESDYnI mission is expected to rely on data and methods similar to that used here. Of course acquisition of SAR and Lidar data sets at nearly the same time, such as envisioned for DESDYnI should improve the results. New airborne contemporaneous NASA UAVSAR and LVIS data are becoming available along with supporting field measurements. The techniques described herein and other methods can be tested with these data sets.

\section{Acknowledgments}

The support to Chinese contributors was from National Basic Research Program of China (Grant no. 2007CB714404) and National Natural Science Foundation of China (Grant nos. 40701124, 40734025). Major work was supported by NASA Remote Sensing
Science (grant number NNG06G133G) and Terrestrial Ecology Program (NNX09AG66G). The LVIS data sets were provided by the Laser Vegetation Imaging Sensor (LVIS) team in the Laser Remote Sensing Branch at NASA Goddard Space Flight Center with support from the University of Maryland, College Park. Funding for the collection and processing of the 2003 Northeastern USA data was provided by NASA's Terrestrial Ecology Program (NASA Grant number NAG512112). ALOS PALSAR data were provided by JAXA EORC. Dr. Joanne Howl assisted with final edits of the manuscript.

\section{References}

Anderson, J. E., Plourde, L. C., Martin, M. E., Braswell, B. H., Smith, M. L., Dubayah, R. O., et al. (2008). Integrating waveform lidar with hyperspectral imagery for inventory of a northern temperate forest. Remote Sensing of Environment, 112(4), 1856-1870.

Askne, J. I. H., Dammert, P. B. G., Ulander, L. M. H., \& Smith, G. (1997). C-band repeatpass interferometric SAR observations of the forest. IEEE Transactions on Geoscience and Remote Sensing, 35, 25-35.

Baccini, A., Laporte, N., Goetz, S. J., Sun, M., \& Dong, H. (2008). A first map of tropical Africa's above-ground biomass derived from satellite imagery. Environmental Research Letters, 3, 1-9.

Blackard, J. A., Finco, M. V., Helmer, E. H., Holden, G. R., Hoppuse, M. L., Jacobsf, D. M., et al. (2008). Mapping U.S. forest biomass using nationwide forest inventory data and moderate resolution information. Remote Sensing of Environment, 112, 1658-1677.

Blair, J. B., Hofton, M. A., \& Rabine, D. L. (2006). Processing of NASA LVIS elevation and canopy (LGE, LCE and LGW) data products, version 1.01. http://lvis.gsfc.nasa.gov

Blair, J. B., Rabine, D. L., \& Hofton, M. A. (1999). The laser vegetation imaging sensor (LVIS): A medium-altitude, digitations-only, airborne laser altimeter for mapping vegetation and topography. ISPRS Journal of Photogrammetry and Remote Sensing, $54,115-122$.

Caicoya, A. T., Kugler, F., Papathanassiou, K., Biber, P., \& Pretzsch, H. (2010). Biomass estimation as a function of vertical forest structure and forest height. Potential and limitations for Radar Remote Sensing. Proc. Of EUSAR 2010 8th European Conference on Synthetic Aperture Radar, 07.-10. June 2010, Eurogress, Aachen, Germany (pp. 901-904).

Cloude, S. R., \& Papathanassiou, K. P. (2003). Three stage inversion process for polarimetric SAR interferometry. IEE Proceedings - Radar Sonar and Navigation, $150(3), 125-134$

Definiens AG. (2009). Definiens Developer 8 Reference Book Version 1.2.0. München, Germany. Definiens AG (p. 276)

Dobson, M. C., Ulaby, F. T., LeToan, T., Beaudoin, A., Kasischke, E. S., \& Christensen, N. (1992). Dependence of radar backscatter on coniferous forest biomass. IEEE Transactions on Geoscience and Remote Sensing, 30, 412-415.

Dobson, M. C., Ulaby, F. T., Pierce, L. E., Sharik, T. L., Bergen, K. M., Kellndorfer, J., et al. (1995). Estimation of forest biophysical characteristics in Northern Michigan with SIR-C/X-SAR. IEEE Transactions on Geoscience and Remote Sensing, 33(4), 877-895.

Donnellan, A., Rosen, P., Graf, J., Leverro, A., Freeman, A., Treuhaft, R., et al. (2008, Mar 01-08). Deformation, Ecosystem Structure, and Dynamics of Ice (DESDynI). IEEE Aerospace Conference, Vols 1-9163-175, MT: Big Sky.

Drake, J. B., Knox, R. G., Dubayah, R. O., Clark, D. B., Condit, R., Blair, J. B., et al. (2003). Above-ground biomass estimation in closed canopy neotropical forests using lidar remote sensing: Factors affecting the generality of relationships. Global Ecology and Biogeography, 12(2), 147-159.

Drake, J. B., Dubayah, R. O., Clark, D. B., Knox, R. G, Blair, J. B., Hofton, M. A et al (2002) Estimation of tropical forest structural characteristics using large footprint lidar. Remote Sensing of Environment, 79, 305-319.

Dubayah, R. O., \& Drake, J. B. (2000). Lidar Remote Sensing for Forestry. Journal of Forestry, 98(6), 44-46.

Efron, B. (1981). Nonparametric estimates of standard error: The jackknife, the bootstrap and other methods. Biometrika, 68, 589-599.

Gaveau, D. A., Balzter, H., \& Plummer, S. (2003). Forest woody biomass classification with satellite-based radar coherence over $900000 \mathrm{~km}^{2}$ in Central Siberia. Forest Ecology and Management, 174(1-3), 65-75.

Hagberg, J. O., Ulander, L. M. H., \& Askne, J. I. H. (1995). Repeat-pass SAR interferometry over forested terrain. IEEE Transactions on Geoscience and Remote Sensing, 33, $331-340$.

Harding, D. J., Blair, J. B., Rabine, D. L., \& Still, K. (1998, June 2). SLICER: Scanning Lidar Imager of Canopies by Echo Recovery instrument and data product description, v. 1.3. : NASA's Goddard Space Flight Center.

Harding, D. J., Blair, J. B., Rodriguez, E., \& Michel, T. (1995). Airborne laser altimetry and interferometric SAR measurements of canopy structure and sub-canopy topography in the Pacific Northwest. Proc. Second Topical Symposium on Combined OpticalMicrowave Earth and Atmosphere Sensing (CO-MEAS'95) (pp. 22-24)..

Hofton, M. A., Rocchio, L. E., Blair, J. B., \& Dubayah, R. (2002). Validation of Vegetation Canopy Lidar sub-canopy topography measurements for a dense tropical forest. Journal of Geodynamics, 34(3), 491-502.

Hyde, P., Dubayah, R., Walker, W., Blair, J. B., Hofton, M., \& Hunsaker, C. (2006). Mapping forest structure for wildlife habitat analysis using multi-sensor (Lidar, SAR/InSAR, ETM+, Quickbird) synergy. Remote Sensing of Environment, 102(2006), 63-73.

Kasischke, E. S., Christensen, N. L., \& Bourgeauchavez, L. L. (1995). Correlating radar backscatter with components of biomass in loblolly-pine forests. IEEE Transactions on Geoscience and Remote Sensing, 33(3), 643-659. 
Kellndorfer, J. M., Walker, W. S., LaPoint, E., Kirsch, K., Bishop, J., \& Fiske, G. (2010) Statistical fusion of lidar, InSAR, and optical remote sensing data for forest stand height characterization: A regional-scale method based on LVIS, SRTM, Landsat ETM+, and ancillary data sets. Journal of Geophysical Research, 115, G00E08. doi: 10.1029/2009JG000997.

Kellndorfer, J. M., Walkera, W., Piercea, L., Dobsona, C., Fitesb, J. A., Hunsakerc, C., et al. (2004). Vegetation height estimation from Shuttle Radar Topography Mission and National Elevation Datasets. Remote Sensing of Environment, 93, 339-358.

Kimes, D. S., Ranson, K. J., \& Sun, G. (1997). Inversion of a backscatter model using neural networks. International Journal of Remote Sensing, 18(10), 2181-2199.

Kobayashi, Y., Sarabandi, K., Pierce, L., \& Dobson, M. C. (2000). An evaluation of the JPL TOPSAR for extracting tree heights. IEEE Transactions on Geoscience and Remote Sensing, 38, 2446-2454.

Kurvonen, L., Pulliainen, J., \& Hallikainen, M. (1999). Retrieval of biomass in boreal forests from multitemporal ERS-1 and JERS-1 SAR images. IEEE Transactions on Geoscience and Remote Sensing, 37(1), 198-205.

Le Toan, T., Beaudoin, A., Riom, J., \& Guyon, D. (1992). Relating forest biomass to SAR data. IEEE Transactions on Geoscience and Remote Sensing, 30, 403-411.

Lefsky, M. A. (2010). A global forest canopy height map from the Moderate Resolution Imaging Spectroradiometer and the Geoscience Laser Altimeter System. Geophysical Research Letters, 37, L15401. doi:10.1029/2010GL043622.

Lefsky, M. A., Cohen, W. B., Acker, S. A., Parker, G. G., Spies, T. A., \& Harding, D. (1999a). Lidar remote sensing of the canopy structure and biophysical properties of Douglas-fir western hemlock forests. Remote Sensing of Environment, 70, 339-361.

Lefsky, M. A., Harding, D., Cohen, W. B., Parker, G., \& Shugart, H. H. (1999b). Surface Lidar remote sensing of basal area and biomass in deciduous forests of Eastern Maryland, USA. Remote Sensing of Environment, 67, 83-98.

Mette, T., Papathanassiou, K., \& Hajnsek, I. (2004). Biomass estimation from polarimetric SAR interferometry over heterogeneous forest terrain. Geoscience and Remote Sensing Symposium, 2004. IGARSS '04. Proceedings Anchorage, Alaska, USA, 20-24 Sept. 2004.

Nelson, R. F., Hyde, P., Johnson, P., Emessiene, B., Imhoff, M. L., Campbell, R., et al. (2007). Invetigation RaDAR-LiDAR synergy in a North Carolina pine forest. Remote Sensing of Environment, 110(1), 98-108.

Nelson, R., Ranson, K. J., Sun, G., Kimes, D. S., Kharuk, V., \& Montesano, P. (2009). Estimating timber volume using MODIS and ICESat/GLAS. Remote Sensing of Environment, 113, 691-701.

Patenaude, G., Milne, R., \& Dawson, T. P. (2005). Synthesis of remote sensing approaches for forest carbon estimation: Reporting to the Kyoto Protocol. Environmental Science \& Policy, 8(2), 161-178.

Ranson, K. J., Lang, R., Sun, G., Chauhan, N., Cacciola, R., \& Kilic, O. (1997a). Mapping of boreal forest biomass from spaceborne synthetic aperture radar. Journal of Geophysical Research, 102(D24), 29,599-29,610.
Ranson, K. J., Saatchi, S., \& Sun, G. (1995). Boreal forest ecosystem characterization with SIR-C/X-SAR. IEEE Transactions on Geoscience and Remote Sensing, 33(4), 867-876.

Ranson, K. J., \& Sun, G. (1994). Mapping biomass for a northern forest ecosystem using multifrequency SAR data. IEEE Transactions on Geoscience and Remote Sensing, 32(2), 388-396.

Ranson, K. J., \& Sun, G. (1996). An evaluation of AIRSAR and SIR-C/X-SAR images of northern forest attributes in Maine, USA. Remote Sensing of Environment, 59, 203-222.

Ranson, K. J., Sun, G., Weishampel, J. F., \& Knox, R. G. (1997b). Forest biomass from combined ecosystem and radar backscatter modeling. Remote Sensing of Environment, 59, 118-133.

Saatchi, S. S., Halligan, K., Despain, D. G., \& Crabtree, R. L. (2007). Estimation of forest fuel load from radar remote sensing. IEEE Transactions on Geoscience and Remote Sensing, 45(6), 1726-1740.

Simard, M., Rivera-Monroy, V. H., Mancera-Pineda, J. E., Castañeda-Moya, E., \& Twilley, R. R. (2008). A systematic method for 3D mapping of mangrove forests based on Shuttle Radar Topography Mission elevation data, ICEsat/GLAS waveforms and field data: Application to Ciénaga Grande de Santa Marta, Colombia. Remote Sensing of Environment, 112, 2131-2144.

Simard, M., Zhang, K. Q., Rivera-Monroy, V. H., Ross, M. S., Ruiz, P. L., Castaneda-Moya E., et al. (2006). Mapping height and biomass of mangrove forests in the Everglades National Park with SRTM elevation data. Photogrammetric Engineering and Remote Sensing, 72(3), 299-312.

S-Plus (2010). S-Plus Overview. TIBCO Spotfire S+. http://spotfire.tibco.com/products/ s-plus/statistical-analysis-software.aspx

Sun, G., Ranson, K. J., Kimes, D. S., Blair, J. B., \& Kovacs, K. (2008). Forest structural parameters from GLAS: An evaluation using LVIS, SRTM data and field measurements. Remote Sensing of Environment, 112(1), 107-117.

Treuhaft, R. N., Madsen, S. N., Moghaddam, M., \& van Zyl, J. J. (1996). Vegetation characteristics and underlying topography from interferometric radar. Radio Science, 31(6), 1449-1485.

Treuhaft, R. N., Law, B. E., \& Asner, G. P. (2004). Forest attributes from radar interferometric structure and its fusion with optical remote sensing. Bioscience, 54, 561-571.

Walker, W. S., Kellndorfer, J. M., LaPoint, E., Hoppus, M., \& Westfall, J. (2007). An empirical SRTM-based approach to mapping vegetation canopy height for the conterminous United States. Remote Sensing of Environment, 109(4), 482-499.

Young, H. E., Ribe, J. H., \& Wainwright, K. (1980, Septemberr). Weight tables for tree and shrub species in Maine. Misc. Report 230. Orono: Life Sciences and Agriculture Experiment Station, University of Maine. 